\title{
Adaptabilidade e estabilidade produtiva de feijão-caupi
}

\author{
Yield adaptability and stability of cowpea
}

\section{Francisco Rodrigues Freire Filho ${ }^{1}$ Maurisrael de Moura Rocha ${ }^{2}$ Valdenir Queiroz Ribeiro ${ }^{3}$ Ângela Celis de Almeida Lopes ${ }^{4}$}

\section{RESUMO}

O objetivo deste trabalho foi avaliar a adaptabilidade e a estabilidade da produtividade de grãos de 15 genótipos de feijão-caupi (Vigna unguiculata) utilizando o modelo de efeitos principais aditivos e interação multiplicativa. Os ensaios foram conduzidos em 13 ambientes, nos Estados do Piaui e Maranhão, no período de 1999 a 2001. Os resultados mostraram a existência de poucas diferenças entre genótipos, mas os efeitos de ambientes, interação genótipos $x$ ambientes $e$ os três primeiros eixos da análise de componentes principais da interação foram altamente significativos $(P<0,01)$. A análise de componentes principais explicou $72,82 \%$ da soma de quadrados da interação genótipos x ambientes. Os genótipos Evx 91-2E e Evx 63-4E aprentam alta adaptabilidade e estabilidade, os quais podem ser cultivados em todos os ambientes do região MeioNorte (Piauí e Maranhão). Os genótipos Evx 47-6E e Evx 92$49 E$ mostraram-se adaptados a ambientes de baixa produtividade, enquanto que o genótipo Evx 63-10E apresentou a maior média e adaptação específica a ambientes de alta qualidade. Os ambientes Brejo-MA, 2001 e Bom Jesus-PI, 2000 foram os mais previsíveis, enquanto Teresina, PI, 2001 e Baixa Grande do Ribeiro, PI, 2001, altamente instáveis. A interação genótipos $x$ ambientes é variável dentro e homogênea entre os Estados do Piauí e Maranhão em termos de qualidade ambiental.

Palavras-chave: Vigna unguiculata, feijão-de-corda, feijão macassar, interação genótipo x ambiente, resposta fenotípica.

\begin{abstract}
The objective of this work was to evaluate the grain yield stability and adaptability of 15 cowpea (Vigna unguiculata) genotypes using the additive main effects and multiplicative interaction model. The trials were carried out at 13 environments of Piaui and Maranhão, Brazil, from 1999 to 2001. Genotype showed low effect, but environment, genotype $x$ environment interaction, and the first tree axes of the principal components analysis were highly significant $(P<0.01)$. The principal components analysis explained $72.82 \%$ of the sum of squares of the genotype $x$ environment interaction. Evx 91-2E and Evx 63-4E genotypes showed high adaptability and stability and can be cultivated in all environments. Evx 47-6E and Evx 92-49E genotypes were adapted to low yield environments, while Evx 63 - 10E genotype had the highest yield averages, and specific adaptation to high quality environments. Brejo, MA, 2001, and Bom Jesus, PI, 2000 environments were the most previsional ones, while Teresina, PI, 2001, and Baixa Grande do Ribeiro, PI, 2001, were higly unstables. The genotype $x$ environment interaction is variable inside and homogeneous between the states of Piauí and Maranhão in terms of environmental quality.
\end{abstract}

Key words: Vigna unguiculata, rope bean, macassar bean, genotype $x$ environment interaction, phenotypic response.

${ }^{1}$ Engenheiro Agrônomo, Doutor, Pesquisador Embrapa Meio-Norte, CP 01, 64006-220, Teresina, PI. E-mail: freire@cpamn.embrapa.br. Autor para correspondência.

${ }^{2}$ Engenheiro Agrônomo, Doutor, Pesquisador Embrapa Meio-Norte. E-mail: mmrocha@cpamn.embrapa.br

${ }^{3}$ Engenheiro Agrônomo, Mestre, Pesquisador Embrapa Meio-Norte. E-mail: valdenir@cpamn.embrapa.br

${ }^{4}$ Engenheiro Agrônomo, Doutor, Professor Universidade Federal do Piauí, Departamento de Biologia, Centro de Ciências da Natureza, 64049-550, Teresina, PI. E-mail: acalopes@bol.com.br 


\section{INTRODUÇÃO}

Em programas de melhoramento, especificamente na etapa de lançamento de cultivares, é de fundamental importância o conhecimento da adaptabilidade e estabilidade dos genótipos, visandose amenizar os efeitos da interação genótipos $\mathrm{x}$ ambientes (GxA) e facilitar a recomendação de cultivares. Em feijão-caupi (Vigna unguiculata), vários trabalhos têm sido feitos para estudar a adaptabilidade e estabilidade de genótipos, com predominância do uso de metodologias que utilizam regressão linear (FINLAY \& WILKINSON, 1963; EBERHART \& RUSSELL, 1966). Esses estudos têm subsidiado o melhoramento e o lançamento de cultivares de feijãocaupi em vários Estados do Nordeste (FREIRE FILHO et al., 2001; 2002).

Atualmente, têm-se buscado modelos alternativos de análises que expliquem melhor o comportamento de genótipos frente às variações ambientais. Nesse sentido, vem aumentando o uso do modelo de efeitos principais aditivos e interação multiplicativa (AMMI), o qual combina a análise de variância dos efeitos aditivos de genótipos e ambientes com a análise de componentes principais do efeito multiplicativo da GxA (ZOBEL et al., 1988; DUARTE \& VENCOVSKY, 1999). FREIRE FILHO et al. (2003) identificaram genótipos de feijão-caupi de porte enramador com adaptação ampla e específica por meio da análise gráfica em biplot (representação gráfica contendo duas categorias de pontos ou marcadores, sendo uma os genótipos e outra os ambientes), utilizando o modelo AMMI. Alguns estudos têm sido feitos comparando o modelo AMMI com a regressão linear e a conclusão predominante é que o primeiro tem sido mais eficiente em explicar a interação GxA (ZOBEL et al., 1988; ROCHA, 2002).

O objetivo deste trabalho foi avaliar a adaptabilidade e a estabilidade da produtividade de grãos de 15 genótipos de feijão-caupi de porte semiereto e de tegumento mulato utilizando o modelo AMMI.

\section{MATERIAL E MÉTODOS}

Foram utilizados dados de produtividade de grãos de genótipos provenientes dos ensaios estaduais de porte semi-ereto e de tegumento mulato do programa de melhoramento de feijão-caupi da Embrapa Meio-Norte, Teresina, PI. Os experimentos foram conduzidos no período de 1999 a 2001, em locais dos Estados do Piauí (PI) e Maranhão (MA). Os tratamentos consistiram de 15 genótipos (14 linhagens e uma cultivar): Evx41-5E (BR 9-Longá X CNCx1601), Evx42-13E (BR 9-Longá X CNCx926-4E), Evx47-6E (CNCx126-5F X CNCx1601), Evx63-1E (CNCx926-5F X Paulista), Evx63-4E (CNCx926-5F X Paulista), Evx63-8E (CNCx926-5F X Paulista), Evx6310E (CNCx926-5F X Paulista), Evx63-13E (CNCx9265F X Paulista), Evx63-14E (CNCx926-5F X Paulista), Evx80-6E/63 (CNC 1735 X F Evx63), Evx83-13E (Paulista X BR 9-Longá), TE93-242-10E-6-1 (Paulista X BR 9-Longá), Evx92-49E (CNC 1735 X F Evx63), Evx91-2E (Evx63A X CNC 1735) e Vita 7 [IITANigériaPiauí - Tvx289-4G]. A cultivar Vita 7 foi utilizada como testemunha.

Os ambientes de avaliação consistiram da combinação de local e ano, o que resultou em 13 ambientes: Baixa Grande do Ribeiro, PI, 2000: BG00; Baixa Grande do Ribeiro, PI, 2001: BG01, Barra do Corda, MA, 2000: BC00 ; Barra do Corda, MA, 2001: BC01; Bom Jesus, PI, 2000: BJ00; Brejo, MA, 2001: BR01; Castelo do Piauí, PI, 2000: CA00; Palmeira do Piauí, PI, 2001: PA01; Sambaíba, MA, 2000: SA00; Sambaíba, MA, 2001: SA01; São Domingos do Azeitão, MA, 1999: SD99; Teresina, PI, 2000: TE00; Teresina, PI, 2001: TE01. Dados de coordenadas geográficas, tipo de solo e pluviosidade média anual dos locais de condução dos experimentos são mostrados na tabela 1 .

Utilizou-se o delineamento experimental de blocos completos casualizados, com quatro repetições. A parcela experimental teve dimensão de 2 x $5 \mathrm{~m}$ e compreendeu quatro fileiras. O espaçamento adotado foi de $0,50 \mathrm{~m}$ entre fileiras com 10 plantas por metro linear, após o desbaste. A área útil da parcela foi representada pelas duas fileiras centrais.

Os dados de produtividade de grãos foram analisados pelo modelo de efeitos principais aditivos e interação multiplicativa (AMMI), o qual representa um modelo linear e bilinear, compreendendo uma análise integrada onde os efeitos aditivos de genótipos e ambientes foram investigados pela análise de variância e o efeito multiplicativo da interação GxA foi decomposto pela análise de componentes principais. A análise considerou os efeitos de genótipos e ambientes como fixos e o modelo segundo equação:

$$
Y_{i j}=\mu+g_{i}+a_{j}+\sum_{k=1}^{n} \lambda_{k} \gamma_{i k} \alpha_{j k}+\rho_{i j}+\varepsilon_{i j}
$$

em que: $Y_{\mathrm{ije} a}$ a média do genótipo i no ambiente j; $\mu$ é a média geral; $g$ e $a_{j}$ são os efeitos do i-ésimo genótipo e j-ésimo ambíente, respectivamente; $\lambda_{\mathrm{k}}$ é o k-ésimo valor singular da matriz GxA; $\gamma_{i k}$ e $\alpha_{j k}$ são os k-ésimos valores singulares correspondentes ao i-ésimo genótipo e j-ésimo ambiente, respectivamente; $\rho_{\mathrm{ij}}$ é o 
Tabela 1 - Coordenadas geográficas dos municípios, tipo de solo e precipitação média anual (pma) das áreas experimentais, nos estados do Piauí e Maranhão.

\begin{tabular}{|c|c|c|c|c|c|}
\hline Municípios & Altitude(m) & Latitude & Longitude & Tipo de solo ${ }^{1}$ & pma (mm) \\
\hline Baixa Grande do Ribeiro, PI & 325 & $07^{\circ} 50^{\prime}$ & $45^{\circ} 12^{\prime}$ & NQ & $1.282,5$ \\
\hline Barra do Corda, MA & 81 & $05^{\circ} 31^{\prime}$ & $42^{\circ} 48^{\prime}$ & LA & $1.835,5$ \\
\hline Bom Jesus, PI & 277 & $09^{\circ} 04^{\prime}$ & $44^{\circ} 21^{\prime}$ & LA & 959,6 \\
\hline Brejo, MA & 50 & $03^{\circ} 41^{\prime}$ & $42^{\circ} 48^{\prime}$ & LA & $1.835,5$ \\
\hline Castelo do Piauí, PI & 250 & $05^{\circ} 20^{\prime}$ & $41^{\circ} 34^{\prime}$ & NF & $1.051,5$ \\
\hline Palmeira do Piauí, PI & 85 & $08^{\circ} 43^{\prime}$ & $44^{\circ} 14^{\prime}$ & LA & $1.339,2$ \\
\hline Sambaíba, MA & 212 & $07^{\circ} 08^{\prime}$ & $45^{\circ} 20^{\prime}$ & AA & $1.030,0$ \\
\hline São Domingos do Azeitão, MA & 310 & $06^{\circ} 49^{\prime}$ & $44^{\circ} 39^{\prime}$ & AA & $1.243,4$ \\
\hline Teresina, PI & 72 & $05^{\circ} 05^{\prime}$ & $42^{\circ} 49^{\prime}$ & NF & $1.360,4$ \\
\hline
\end{tabular}

${ }^{1}$ AA = Argissolo Amarelo, NF = Neossolo Flúvico, NQ: Neossolo quartzarênico, LA: Latossolo Amarelo.

resíduo da interação GxA; n é o número de eixos ou componentes principais da interação (CPI) retidos pelo modelo; e $\varepsilon_{\mathrm{ij}}$ é o erro experimental médio.

A seleção do modelo AMMI foi realizada segundo o critério do teste $F_{R}$ apresentado por PIEPHO (1995), de acordo com a equação:

$$
\mathrm{F}_{\mathrm{R}, \mathrm{n}}=\left(\mathrm{SQ}_{\mathrm{GxA}}-\sum_{\mathrm{k}=1}^{\mathrm{n}} \lambda_{\mathrm{k}}^{2}\right) /\left(\mathrm{f}_{2} \cdot \mathrm{Q} \mathrm{M}_{\text {ErroMédio }}\right)
$$

com $\mathrm{f}_{2}=(\mathrm{g}-1-\mathrm{n})(\mathrm{a}-1-\mathrm{n})$, correspondendo ao número de graus de liberdade associados a cada parcela da interação GxA, sendo g: o efeito de genótipos; a: o efeito de ambientes e n: o número de componentes principais da interação.

Este critério baseia-se na análise do ruído, ou seja, resíduo de cada componente principal que representa a variação aleatória não relacionada com o fenômeno da interação GxA (ZOBEL et al., 1988), sendo selecionado aquele modelo da família AMMI que engloba, pela primeira vez, um eixo em que seu resíduo não seja significativo pelo teste $F_{R}$. A interpretação da adaptabilidade e estabilidade dos genótipos e ambientes foi feita com base na análise gráfica na forma de biplot.

\section{RESULTADOS E DISCUSSÃO}

Os resultados da análise de variância mostraram que apenas os efeitos de ambientes e interação genótipos $\mathrm{x}$ ambientes foram significativos $(\mathrm{P}<0,01)$ (Tabela 2). Esse resultado indica que os genótipos apresentaram uma resposta diferencial em função da variação ambiental. Pelo critério do teste $F_{R}$ (PIEPHO, 1995), o modelo selecionado é o AMMI3, cujo resíduo foi não significativo. O CPI1 explicou 27,30\%, o CPI2 25,18\% e o CPI3 20,34\%. Os três eixos, portanto, explicaram 72,82\% da Soma de Quadrados da interação $\mathrm{GxA}\left(\mathrm{SQ}_{\mathrm{GxA}}\right)$. Isto significa que todo o padrão adjacente à interação $\mathrm{GxA}$ se concentra nos três primeiros eixos. Segundo ROCHA (2002), nos casos em que existe padrão em mais de dois eixos, a princípio, a representação gráfica em biplot não se justificaria; entretanto, este autor comenta que a análise AMMI apresenta como característica principal a captação da maior parte do padrão nos primeiros eixos. De fato, para esses resultados, $72 \%$ desse padrão foi representado pelos dois primeiros eixos. Assim, a interpretação gráfica da estabilidade será feita considerando apenas os biplots com os modelos AMMI1 e AMMI2 (Figuras 1 e 2).

Quatro genótipos apresentaram médias na faixa de $1.300-1.400 \mathrm{~kg} \mathrm{ha}^{-1}$, nove na faixa de 1.200 $1.300 \mathrm{~kg} \mathrm{ha}^{-1} \mathrm{e}$ dois na faixa de $1.100-1.200 \mathrm{~kg} \mathrm{ha}^{-1}$. Nove genótipos (60\% dos genótipos) superaram a média da testemunha Vita 7 (Tabela 3). Com relação aos ambientes, as médias preditas variaram de $455 \mathrm{~kg} \mathrm{ha}^{-1}$ (SD99) a $2.803 \mathrm{~kg} \mathrm{ha}^{-1}$ (SA01).

A interpretação gráfica em biplot foi feita com base na variação devida aos efeitos principais aditivos de genótipos e ambientes e do efeito multiplicativo da interação GxA (Figura 1), bem como apenas com base no efeito multiplicativo da interação GxA (Figura 2). Neste último caso, o efeito da interação GxA é analisado, objetivando confirmar as estabilidades observadas no biplot da figura 1. Observa-se que, praticamente, não há variação em efeitos principais aditivos de genótipos, pois estes se agruparam numa grande coluna central em torno da média geral, indicando que houve variação somente para o efeito multiplicativo da interação GxA (Figura 1). Já os ambientes variaram muito, tanto em efeitos aditivos quanto multiplicativos. Isto mostra que o grupo de genótipos em estudo apresenta poucas diferenças genéticas entre si, enquanto que os 
Tabela 2 - Análise de efeitos principais aditivos e interação multiplicativa relacionada à produtividade de grãos $\left(\mathrm{kg}_{\text {ha }}{ }^{-1}\right)$ para 15 genótipos de feijão-caupi semi-eretos de tegumento mulato, testados em 13 ambientes nos estados do Piauí e Maranhão.

\begin{tabular}{|c|c|c|c|c|}
\hline Causas de variação & GL & $\mathrm{QM}$ & $\% \mathrm{SQ}_{\mathrm{GxA}} / \mathrm{CPI}^{1}$ & $\% \mathrm{SQ}_{\mathrm{GxA}}$ Acumulada \\
\hline Genótipos (G) & 14 & $59070,59^{\mathrm{ns}}$ & - & - \\
\hline Ambientes (A) & 12 & $8311932,87 * *$ & - & - \\
\hline G x A & 168 & $43543,90 * *$ & - & - \\
\hline EPI1 & 25 & $79895,17^{* *}$ & 27,30 & 27,30 \\
\hline Resíduo $_{\text {АммI1 }}$ & 143 & $37188,80^{* *}$ & & \\
\hline CPI2 & 23 & $80074,87 * *$ & 25,18 & 52,48 \\
\hline Resíduo $_{\text {AмmI2 }}$ & 120 & $28968,98^{* *}$ & & \\
\hline СPI3 & 21 & $70865,59 * *$ & 20,34 & 72,82 \\
\hline Resíduo $_{\text {АммІз }}$ & 99 & $20081,86^{\mathrm{ns}}$ & 27,18 & 100,00 \\
\hline Erro médio/r ${ }^{2}$ & 585 & 14662,25 & & \\
\hline
\end{tabular}

${ }^{1}$ Porcentagem da soma de quadrados da interação genótipos x ambientes captada por CPI (componente principal da interação). ${ }^{2}$ Número de repetições $=4 .{ }^{\text {ns }}$ Não significativo $(\mathrm{P}<0,01) . * *$ Significativo $(\mathrm{P}<0,01)$.

ambientes, alta variabilidade. Isso corrobora com os dados observados na Tabela 1, principalmente, em termos de altitude, latitude, tipo de solo e pluviosidade. Somam-se a esses, os efeitos ambientais imprevisíveis, como os veranicos, que acentuam as irregularidades pluviométricas.

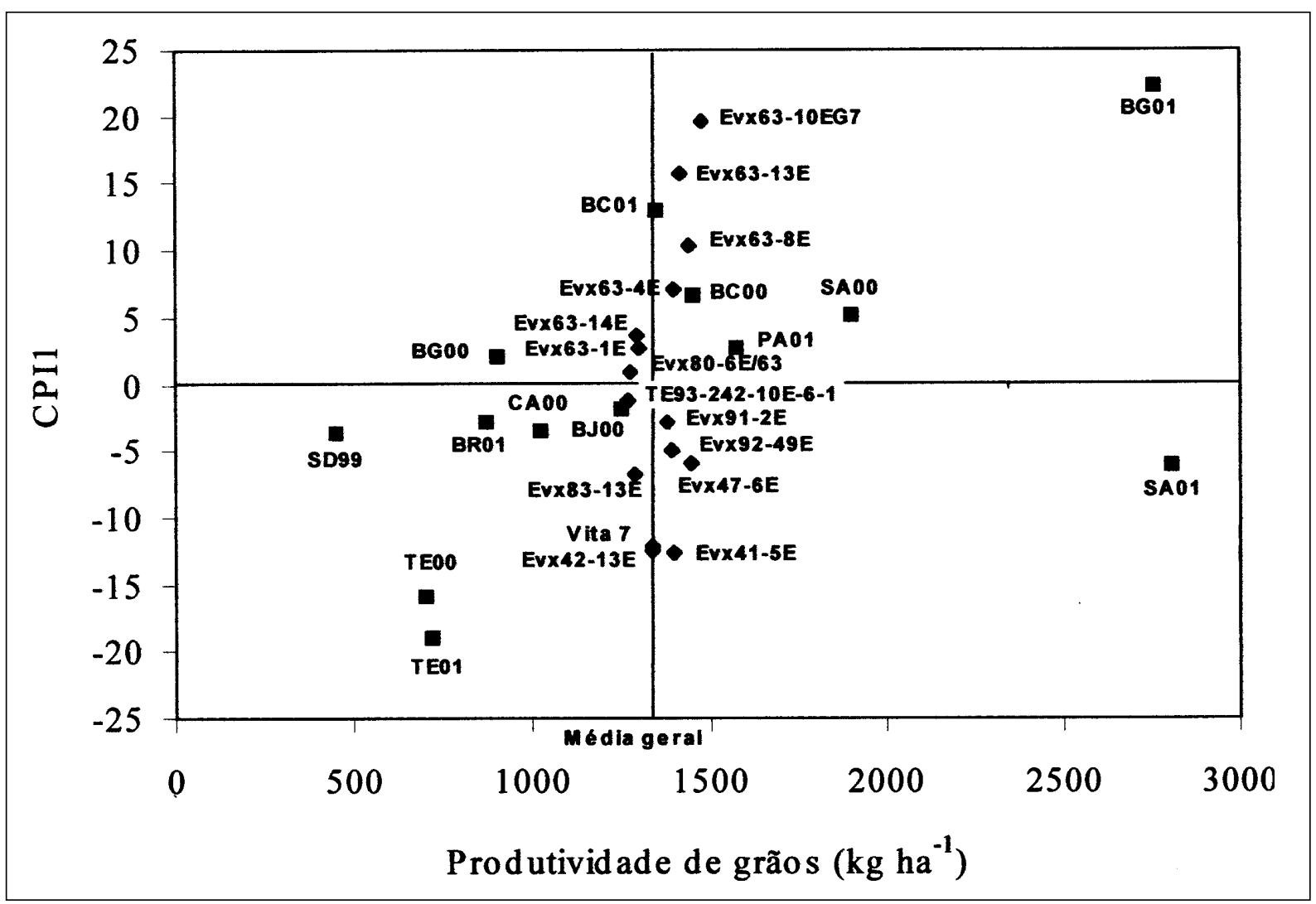

Figura 1 - Primeiro componente principal da interação (CPI1) x produtividade de grãos, de 15 genótipos ( $\bullet$ ) de feijão-caupi semi-eretos de tegumento mulato, avaliados em 13 ambientes (ם) do Meio-Norte do Brasil (BG00: Baixa Grande do Ribeiro, PI, 2000; BG01: Baixa Grande do Ribeiro, PI, 2001; BC00: Barra do Corda, MA, 2000; BC01: Barra do Corda, MA, 2001; BJ00: Bom Jesus, PI, 2000; BR01: Brejo, MA, 2001; CA00: Castelo do Piauí, PI, 2000; PA01: Palmeira do Piauí, PI, 2001; SA00: Sambaíba, MA, 2000; SA01: Sambaíba, MA, 2001; SD99: São Domingos do Azeitão, MA, 1999; TE00: Teresina, PI, 2000; TE01: Teresina, PI, 2001). 


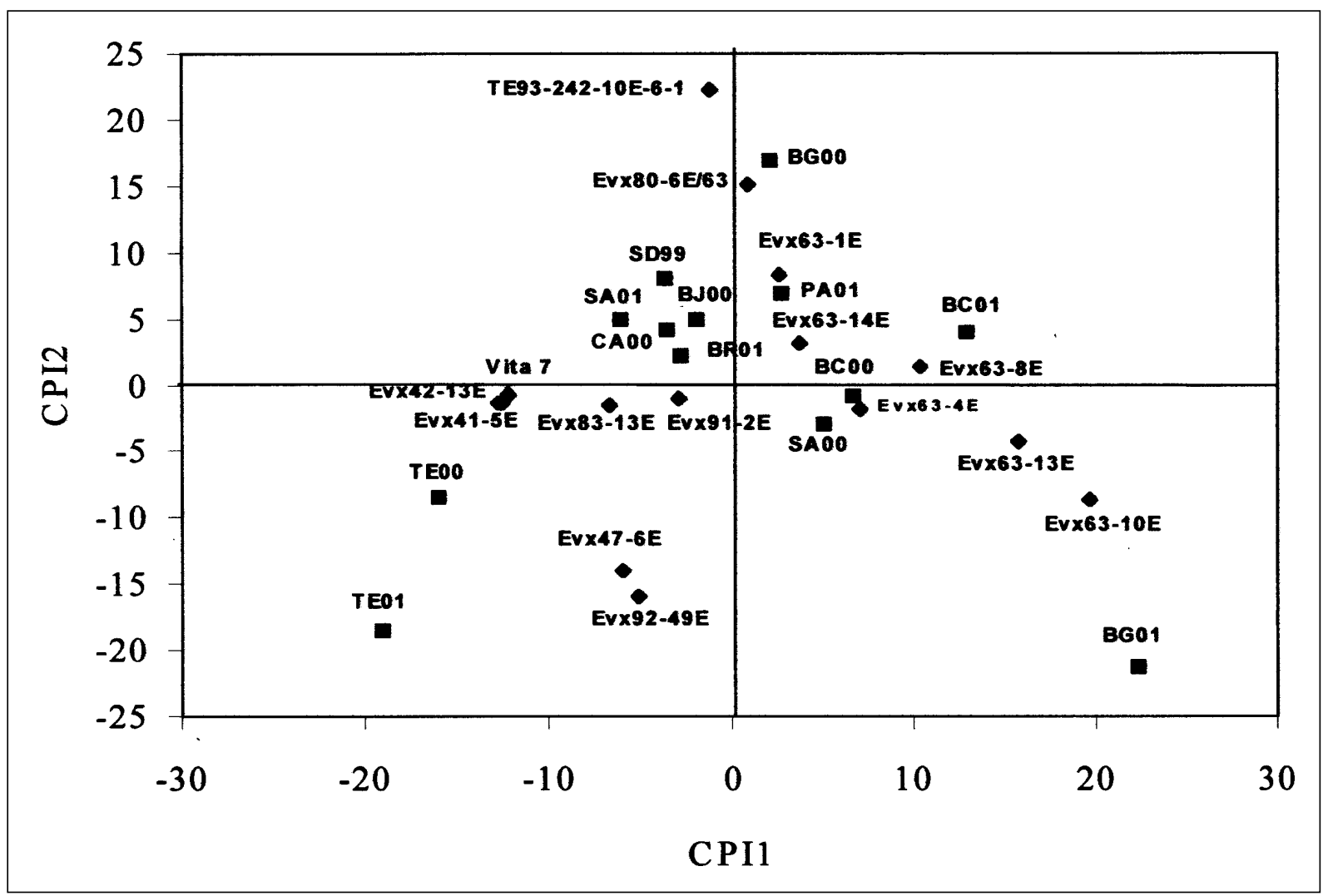

Figura 2 - Primeiro componente principal da interação (CPI1) x segundo componente principal da interação (CPI2), de 15 genótipos $(\bullet)$ de feijão-caupi semi-eretos de tegumento mulato, avaliados em 13 ambientes ( $\boldsymbol{\square})$ do Meio-Norte do Brasil (BG00: Baixa Grande do Ribeiro, PI, 2000; BG01: Baixa Grande do Ribeiro, PI, 2001; BC00: Barra do Corda, MA, 2000; BC01: Barra do Corda, MA, 2001; BJ00: Bom Jesus, PI, 2000; BR01: Brejo, MA, 2001; CA00: Castelo do Piauí, PI, 2000; PA01: Palmeira do Piauí, PI, 2001; SA00: Sambaíba, MA, 2000; SA01: Sambaíba, MA, 2001; SD99: São Domingos do Azeitão, MA, 1999; TE00: Teresina, PI, 2000; TE01: Teresina, PI, 2001).

Como, para a grande maioria dos experimentos, os coeficentes de variação sugeriram padrão aceitável de precisão experimental na obtenção das médias de produtividades de grãos (Tabela 3), a baixa variabilidade do efeito de genótipos pode ter sido causada pelo parentesco existente entre estes, já que para os genitores BR 9-Longá, Paulista, CNCx1601, CNCx926-5F e CNC 1735 são comuns às genealogias da maioria dos genótipos. Outro fator que pode ter contribuído para a redução da variabilidade genética foi a forte pressão de seleção exercida para aumentar o peso de 100 grãos e outros componentes de produtividade voltados para a qualidade, na fase de avaliação preliminar das linhagens. Baixa variabilidade em feijão-caupi também foi obtida por FREIRE FILHO et al. (2002 e 2003), em estudos sobre adaptabilidade e estabilidade fenotípica compreendendo um grupo de genótipos de porte enramador.

Para efeito de interpretação dos resultados quanto à adaptabilidade e estabilidade, neste trabalho, a expressão alta adaptabilidade será utilizada como sinônimo de alta produtividade, e a expressão ampla adaptabilidade, como sinônimo de alta estabilidade, conforme FREIRE FILHO et al. (2003). Os genótipos mais produtivos foram Evx415E, Evx47-6E, Evx63-4E, Evx63-8E, Evx63-10E, Evx6313E, Evx92-49E e Evx91-2E, com produtividades acima da média geral (1.365kg ha-1) (Figura 1 e Tabela 3). Desses, os mais estáveis foram, hierarquicamente, Evx91-2E (1ํㅜ) e Evx63-4E, que também apresentaram superioridade de adaptabilidade e estabilidade em relação à testemunha Vita 7 (Figuras 1 e 2) e, portanto, podem ser cultivados em todos os ambientes estudados.

Foram verificadas similaridades em termos de interação GxA entre os genótipos Evx41-5E, Evx4213E e Vita 7; entre Evx47-6E e Evx92-49E; entre Evx634E e Evx63-8E; e entre Evx80-6E/63 e TE93-242-10E-61 (Figura 2). As similaridades entre os genótipos Evx41-5E e Evx42-13E, e entre Evx80-6E/63 e TE92-242- 
Tabela 3 - Médias preditas para o caráter produtividade de grãos ( $\mathrm{kg} \mathrm{ha}^{-1}$ ) pelo modelo de efeitos principais aditivos e interação multiplicativa, considerando os três primeiros eixos da análise de componentes principais da interação (AMMI3) para 15 genótipos de feijão-caupi semi-eretos de tegumento mulato, testados em 13 ambientes nos estados do Piauí e Maranhão.

\begin{tabular}{|c|c|c|c|c|c|c|c|c|c|c|c|c|c|c|}
\hline \multirow{2}{*}{ Genótipos } & \multicolumn{13}{|c|}{ Ambiente $^{1}$} & \multirow{2}{*}{ Média } \\
\hline & TE00 & TE01 & CA00 & PA01 & BJ00 & BG00 & BG01 & SD99 & BR01 & BC00 & BC01 & SA00 & SA01 & \\
\hline Evx41-5E & 1.243 & 833 & 1.229 & 1.577 & 1.438 & 992 & 2.467 & 478 & 834 & 1.418 & 1.103 & 2.159 & 2.336 & 1.294 \\
\hline Evx42-13E & 831 & 954 & 1.017 & 1.506 & 1.221 & 809 & 2.466 & 477 & 894 & 1.334 & 1.172 & 1.748 & 2.969 & 1.243 \\
\hline Evx47-6E & 941 & 1.167 & 1.051 & 1.545 & 1.256 & 715 & 3.017 & 454 & 957 & 1.505 & 1.323 & 1.942 & 2.958 & 1.345 \\
\hline Evx63-1E & 468 & 446 & 966 & 1.577 & 1.201 & 965 & 2.585 & 456 & 840 & 1.395 & 1.375 & 1.770 & 2.868 & 1.208 \\
\hline Evx63-4E & 617 & 634 & 1.022 & 1.618 & 1.257 & 913 & 2.989 & 452 & 894 & 1.533 & 1.477 & 1.955 & 2.823 & 1.299 \\
\hline Evx63-8E & 464 & 614 & 1.015 & 1.687 & 1.255 & 973 & 3.064 & 524 & 973 & 1.587 & 1.616 & 1.892 & 3.082 & 1.339 \\
\hline Evx63-10E & 560 & 604 & 1.031 & 1.683 & 1.280 & 903 & 3.491 & 428 & 927 & 1.701 & 1.688 & 2.125 & 2.780 & 1.372 \\
\hline Evx63-13E & 630 & 492 & 1.050 & 1.650 & 1.298 & 949 & 3.233 & 407 & 857 & 1.621 & 1.561 & 2.132 & 2.578 & 1.319 \\
\hline Evx63-14E & 628 & 453 & 998 & 1.547 & 1.232 & 927 & 2.689 & 389 & 780 & 1.413 & 1.317 & 1.922 & 2.575 & 1.206 \\
\hline Evx80-6E/63 & 520 & 281 & 1.022 & 1.600 & 1.260 & 1.089 & 2.359 & 478 & 801 & 1.361 & 1.317 & 1.819 & 2.690 & 1.186 \\
\hline Evx83-13E & 748 & 765 & 974 & 1.476 & 1.188 & 790 & 2.564 & 394 & 812 & 1.336 & 1.185 & 1.798 & 2.760 & 1.200 \\
\hline TE93-242-10E-6-1 & 396 & 226 & 1.013 & 1.634 & 1.252 & 1.167 & 2.174 & 550 & 845 & 1.330 & 1.346 & 1.692 & 2.905 & 1.182 \\
\hline Evx92-49E & 922 & 1.115 & 1.000 & 1.482 & 1.206 & 643 & 3.016 & 378 & 887 & 1.460 & 1.261 & 1.930 & 2.828 & 1.296 \\
\hline Evx91-2E & 923 & 712 & 1.118 & 1.587 & 1.340 & 950 & 2.697 & 456 & 851 & 1.461 & 1.274 & 2.048 & 2.558 & 1.285 \\
\hline Vita $7^{2}$ & 616 & 1.025 & 927 & 1.499 & 1.130 & 742 & 2.521 & 502 & 953 & 1.326 & 1.254 & 1.559 & 3.335 & 1.243 \\
\hline Média & 700 & 688 & 1.029 & 1.578 & 1.254 & 902 & 2.756 & 455 & 874 & 1.452 & 1.351 & 1.899 & 2.803 & 1.365 \\
\hline CV(\%) & 32,3 & 35,6 & 16,9 & 11,3 & 16,5 & 24,0 & 13,9 & 36,0 & 24,5 & 15,1 & 15,5 & 19,6 & 13,1 & 21,1 \\
\hline
\end{tabular}

${ }^{1}$ Baixa Grande do Ribeiro, PI, 2000: BG00; Baixa Grande do Ribeiro, PI, 2001: BG01; Barra do Corda, MA, 2000: BC00; Barra do Corda, MA, 2001: BC01; Bom Jesus, PI, 2000: BJ00; Brejo, MA, 2001: BR01; Castelo do Piauí, PI, 2000: CA00; Palmeira do Piauí, PI, 2001: PA01; Sambaíba, MA, 2000: SA00; Sambaíba, MA, 2001: SA01; São Domingos do Azeitão, MA, 1999: SD99; Teresina, PI, 2000: TE00; Teresina, PI, 2001: TE01.

${ }^{2}$ Testemunha.

10E-6-1 também é genética, pois apresentam alto grau de parentesco, já que estes têm um ancestral comum em suas genealogias. Quanto aos demais, a similaridade em termos de interação GxA não foi acompanhada de similaridade genética, a exemplo do resultado obtido por FREIRE FILHO et al. (2003).

Quanto à adaptação específica, destacouse o genótipo Evx63-10E, que apresentou a maior média (1.372 $\left.\mathrm{kg} \mathrm{ha}^{-1}\right)$, podendo ser cultivado em ambientes de alta produtividade, como Barra do Corda, MA, 2001 e Baixa Grande do Ribeiro, PI, 2001 (Figura 2 e Tabela 3). Adaptação específica positiva também foi encontrada entre os genótipos Evx80-6E/63 e TE92-242-10E-6-1 com o ambiente BG00, e de Evx63-4E com o ambiente BC00. Os genótipos Evx47-6E e Evx92-49E mostraram-se bem adaptados, no entanto apresentaram alta interação com o ambiente (Figuras 1 e 2 e Tabela 3).

Os ambientes mais estáveis foram BC00, BR01, CA00, BJ00 e SA00 (Figura 2); destes, o ambiente Sambaíba, MA, 2000, foi o mais produtivo. Segundo OLIVEIRA et al. (2003), a estabilidade ambiental tem grande importância, pois informa sobre a confiabilidade no ordenamento dos genótipos em um dado ambiente de teste, em relação à classificação para a média dos ambientes testados. A estabilidade do local Bom Jesus, PI, e a instabilidade do local Teresina, PI, confirma os resultados obtidos por FREIRE FILHO et al. (2003), em um estudo compreendendo genótipos de feijão-caupi enramador. Como exemplo de ambientes similares quanto à interação GxA, citam-se CA00, BJ00, SD99 e BR01; e BC00 e SA00 (Figura 2). Não houve tendência de agrupamento quanto à interação entre ambientes pertencentes ao Estado do Maranhão ou Piauí, mostrando que a interação foi dissimilar para ambientes dentro de cada Estado.

A interpretação gráfica em biplot na análise AMMI evidenciou que a maioria dos genótipos apresentou interação específica positiva com os ambientes. A análise permitiu selecionar de forma fácil e prática os genótipos mais estáveis e com produtividades acima da média.

\section{CONCLUSÕES}

Os genótipos Evx91-2E e Evx63-4E reúnem adaptabilidde e estabilidade e podem ser cultivados em todos os ambientes estudados, enquanto o genótipo Evx63-10E expressa melhor o potencial 
genético em ambientes de alta produtividade. A interação genótipo $\mathrm{x}$ ambiente é variável dentro e homogênea entre os Estados do Piauí e Maranhão em termos de qualidade ambiental. O local Sambaíba, MA, apresenta adaptabilidade e estabilidade satisfatórias, enquanto o local Teresina, PI, é imprevisível e associado com baixas produtividades.

\section{REFERÊNCIAS BIBLIOGRÁFICAS}

DUARTE, J.B.; VENCOVSKY, R. Interação genótipos x ambientes: uma introdução à análise AMMI. Ribeirão Preto: Sociedade Brasileira de Genética, 1999. 60p. (Série Monografias, 9).

EBERHART, S.A.; RUSSELL, W.A. Stability parameters for comparing varieties. Crop Science, Madison, v.6, n.1, p.3640, 1966.

FINLAY, K.W.; WILKINSON, G.N. The analysis of adaptation in a plant-breeding programme. Australian Journal of Agricultural Research, Collingwood, v.14, n.5, p.742-754, 1963.

FREIRE FILHO, F.R. et al. Adaptabilidade e estabilidade de rendimento de grãos de genótipos de caupi de porte semi-ereto. Revista Científica Rural, Bagé, v.6, n.2, p.31-39, 2001.
FREIRE FILHO, F.R. et al. Adaptabilidade e estabilidade da produtividade de grãos de linhagens de caupi de porte enramador. Revista Ceres, Viçosa, MG, v.49, n.284, p.383393, 2002.

FREIRE FILHO, F.R. et al. Adaptabilidade e estabilidade da produtividade de grãos de caupi enramador de tegumento mulato. Pesquisa Agropecuária Brasileira, Brasília, v.38, n.5, p.591-598, 2003.

OLIVEIRA, A.B. de et al. Emprego da análise AMMI na avaliação da estabilidade produtiva em soja. Pesquisa Agropecuária Brasileira, Brasília, v.38, n.3, p.357-364, 2003.

PIEPHO, H.P. Robustness of statistical test for multiplicative terms in the additive main effects and multiplicative interaction model for cultivar trial. Theoretical and Applied Genetics, Berlin, v.90, n.3/4, p.438-443, 1995.

ROCHA, M. de M. Seleção de linhagens experimentais de soja para adaptabilidade e estabilidade fenotípica. 2002. 174f. Tese (Doutorado em Genética e Melhoramento de Plantas) - Curso de Pós-graduação em Agronomia, Escola Superior de Agricultura "Luiz de Queiroz", Universidade de São Paulo.

ZOBEL, R.W. et al. Statistical analysis of a yield trial. Agronomy Journal, Madison, v.80, n.3, p.388-393, 1988. 